\title{
Romatoid Artritte Tıbbi Beslenme Tedavisine Yönelik Yaklaşımlar
}

\author{
Approaches to Medical Nutrition Therapy in Rheumatoid Arthritis
}

\author{
Gülşah Kaner¹, Gamze Çalık², Ebru Eren³, Vedat Gerdan ${ }^{4}$
}

Geliş tarihi/Received: 02.12.2020 • Kabul tarihi/Accepted: 24.03.2020

\section{ÖZET}

Romatoid artrit eklemlerde ilerleyici yıkıma neden olan, kronik seyirli inflamatuvar otoimmün bir hastalıktır. Yaşam kalitesini ciddi şekilde etkileyen bu hastalık, en sık 40-50’li yaşlarda başlamakta ve kadınlarda erkeklere göre daha sık görülmektedir. Romatoid artritli hastalarda inflamasyonu azaltmak, antioksidan kapasiteyi artırmak ve lipit profilini iyileştirmek amacıyla beslenme tedavisine yönelik farklı yaklaşımlar incelenmektedir. Romatoid artrit hastalarının tıbbi beslenme tedavisinde ele alınan diyet modelleri arasında Akdeniz diyeti, anti-inflamatuvar diyet ve glutensiz diyet bulunmaktadır. Akdeniz diyetinin inflamatuvar belirteçlerde, hastalık aktivitesinde ve kardiyovasküler risk faktörlerinde azalmaya neden olabileceği belirtilmiştir. Genel olarak Akdeniz diyetine benzer özellikler taşıyan anti-inflamatuvar diyetin romatoid artrit üzerine olumlu etkileri olabileceği öne sürülmüş olmakla birlikte, hastalık aktivitesini azaltmaya yönelik yeterli kanıt bulunmamaktadır. Çölyak hastalarının tıbbi beslenme tedavisinde kullanılan glutensiz diyetin, romatoid artrit hastalarında da kullanılabileceği düşünülmektedir. Bu derlemede; romatoid artritte beslenme tedavisine yönelik farklı yaklaşımların hastalık aktivitesi üzerine etkisinin belirlenmesi amaçlanmıştır.

Anahtar kelimeler: Romatoid artrit, Akdeniz diyeti, anti-inflamatuvar diyet, glutensiz diyet

\begin{abstract}
Rheumatoid arthritis is a chronic inflammatory autoimmune disease that causes progressive destruction of the joints. The disease seriously affects the quality of life with increased morbidity and decreased life expectancy. Rheumatoid arthritis, which starts at the ages of 40-50 most frequently, is more common in women than in men. Dietary modifications can be used for reducing inflammation, increasing antioxidant levels, changing lipid profile in patients with rheumatoid arthritis. The diet models include the Mediterranean diet, anti-inflammatory diet and gluten-free diet. It is stated that the Mediterranean diet model may cause a decrease in inflammatory markers, disease activity and cardiovascular risk factors. Although it has been suggested that the anti-inflammatory diet, which is generally similar to the Mediterranean diet, may have positive effects on rheumatoid arthritis, there is insufficient evidence to reduce disease activity. It is thought that the gluten-free diet used in celiac patients can also be used in patients with rheumatoid arthritis. In this review, it is aimed to determine the effect of different diet approaches on disease activity.
\end{abstract}

Keywords: Rheumatoid arthritis, Mediterranean diet, anti-inflammatory diet, gluten-free diet

1. İletişim/Correspondence: İzmir Kâtip Çelebi Üniversitesi, Sağlık Bilimleri Fakültesi, Beslenme ve Diyetetik Bölümü, İzmir, Türkiye

E-posta: kanergulsah@gmail.com • • https://orcid.org/0000-0001-5882-6049

2. ̇̇mir Kâtip Çelebi Üniversitesi, Sağlık Bilimleri Fakültesi, Beslenme ve Diyetetik Bölümü, İzmir, Türkiye • ๑ https://orcid.org/0000-0002-9160-7750
3. ̇zmir Kâtip Çelebi Üniversitesi, Sağlık Bilimleri Fakültesi, Beslenme ve Diyetetik Bölümü, İzmir, Türkiye • ๑ https://orcid.org/0000-0001-5069-730X

4. Bakırçay Üniversitesi, Çiğli Eğitim ve Araştırma Hastanesi, İzmir, Türkiye 으 https://orcid.org/0000-0001-8501-6172 


\section{GİRIŞ}

Romatoid artrit (RA), dünya nüfusunun yaklaşık olarak \%1-2'sini etkileyen kronik, ağrıll, eklemlerde ilerleyici yıkıma neden olan inflamatuvar ve otoimmün bir hastalıktır. Hastalık, artan morbidite ve azalmış yaşam beklentisi ile yaşam kalitesini ciddi şekilde etkilemektedir (1). Romatoid artrit, kadınlarda erkeklere göre daha sık görülmekle birlikte, en sık 4050’li yaşlarda ortaya çıkmaktadır (2).

Romatoid artritin etiyolojisi tam olarak bilinmemektedir. Ancak, inflamatuvar sitokinlerin [tümör nekroz faktörü-a (TNF-a), interlökin-1 (IL-1), interlökin-6 (IL-6)] üretimi ve hücre aracılı bağışıklık yanıtın artışı gibi bağışıklık mekanizmalarının RA oluşumunda önemli rol oynadığı bilinmektedir. Oksidatif stres, inflamasyonun nedeni veya sonucu olarak ortaya çıkmaktadır (3). Hem genetik hem de yaşam tarzı ve diyet gibi çevresel faktörlerin RA gelişimine katkıda bulunduğu yaygın olarak kabul edilmektedir (2).

Romatoid artritli hastalardaki kronik inflamasyon, aterom plak oluşumunu indükleyebilen endotel hücre aktivasyonunu ve vasküler disfonksiyonu artırmaktadır. TNF- $\alpha$, IL-1, interlökin-17 (IL-17) gibi sitokinler ile C-reaktif protein (CRP) ve serum amiloid P gibi akut faz reaktanları aterojenik mekanizmalardan sorumlu mediyatörlerdir. $\mathrm{Bu}$ mekanizmalar nedeniyle, RA'lı hastalarda kardiyovasküler hastalık riskinin daha yüksek olduğu bildirilmektedir. Ayrıca, TNF-a gibi pro-inflamatuvar moleküller insülin duyarlılığını doğrudan etkileyerek, bu hastalarda insülin direncini artırabilmektedir (4).

Antioksidan vitaminler (A, C ve E) ve mineraller (selenyum, çinko) ile omega-3 çoklu doymamış yağ asitlerinin inflamasyon ve ağrı üzerine etkileri olduğu bilinmektedir. $\mathrm{Bu}$ besin ögelerinin, antioksidan ve anti-inflamatuvar özelliklerinden dolayı serbest radikal oluşumu ve sitokin düzeylerinin artışının önlenmesinde etkili olduğu gösterilmiştir $(5,6)$. Romatoid artritli hastaların beslenme durumlarının incelendiği bir çalışmada; enerjinin karbonhidrattan gelen oranının düşük, doymuş yağ oranın ise yüksek olduğu belirlenmiş, bu sonucun da kardiyovasküler hastalık riskinin artmasında etkili olabileceği belirtilmiştir (7). $\mathrm{Bu}$ hastalarda diyetle protein, kalsiyum, folat, çinko, magnezyum, $\mathrm{B}_{6}$ ve E vitamini alımlarının da yetersiz olduğu belirlenmiştir (8). Türkiye'de 35-64 yaş arası 71 RA tanılı kadın hastanın beslenme durumunun değerlendirildiği bir çalışmada, hastaların diyetle günlük ortalama enerji, karbonhidrat, demir, kalsiyum ve potasyum alımlarının gereksinimlerinin altında olduğu saptanmıştır (9). Ayrıca, beslenme durumunun değerlendirildiği biyokimyasal parametreler olan serum albumin, folik asit ve demir düzeylerinin de bu hastalarda düşük olduğu belirlenmiştir (7).

Romatoid artrit tanılı hastalarda, uygun bir beslenme tedavisinin benimsenmesi ve sürdürülmesi hastalığın iyileşmesi ve remisyonun sağlanmasına katkıda bulunmaktadır (5,6). Genel olarak romatolojik hastalıklarda diyetle yeterli protein ve enerji alıminın, antioksidan vitamin ve mineraller ile omega-3 çoklu doymamış yağ asitlerinden zengin beslenmenin, doku hasarını önleyebileceği ve inflamatuvar süreci baskılayabileceği bildirilmiştir. Bireylerin enerji gereksinimleri, vücut ağırlığı ve fiziksel aktivite düzeylerine göre ayarlanmalıdır. Yetersiz beslenen veya hastalığın inflamatuvar fazında olan bireyler için protein gereksinimi 1.5-2 g/ kg/gün’dür. Yağların, günlük enerjinin \%30'undan az olacak şekilde alınması gerekmektedir. Diyetin yağ asidi örüntüsünde omega-3 yağ asitlerinin (özellikle eikosapentaenoik asit ve dekosaheksaenoik asit) artırılması, inflamatuvar süreci azaltarak hastalık sürecine olumlu etkilerde bulunmaktadır. Romatoid artrit hastalarında antioksidan özellik gösteren A, C ve $\mathrm{E}$ vitaminleri ile selenyum, çinko gibi minerallerin önerilen düzeyde alınması oldukça önemlidir. Ayrıca, bu hastalarda yeterli miktarda folat, $\mathrm{B}_{6}$ ve $\mathrm{B}_{12}$ vitaminleri alımı teşvik edilmelidir. Bunların yanı sıra, D vitamini düzeyi değerlendirilmeli ve normalin altında ise D vitamini desteği yapılmalıdır (10). Romatoid artritli hastalarda inflamasyonu azaltmak, antioksidan seviyelerini artırmak ve lipit profilini 
iyileştirmek amacıyla beslenme tedavisine yönelik farklı yaklaşımlar incelenmektedir (11). Romatoid artrit hastalarının tıbbi beslenme tedavisinde ele alınan diyet modelleri arasında Akdeniz diyeti, antiinflamatuvar diyet ve glutensiz diyet bulunmaktadır. $\mathrm{Bu}$ derlemede, RA'nın beslenme tedavisine yönelik yaklaşımların incelenmesi amaçlanmıştır.

\section{Akdeniz Diyeti ve Antiinflamatuvar Diyet}

Akdeniz diyeti temel yağ kaynağı zeytinyağı olan, rafine edilmemiş tahıllar, sebze ve meyveler, kurubaklagiller, yağlı tohumlar gibi bitkisel besinlerin tüketiminin yüksek; balık ve deniz ürünleri, yumurta, kümes hayvanları, süt ürünleri (az yağlı yoğurt ve peynir) ile alkollü içecek (özellikle şarap) tüketiminin orta düzeyde olduğu, kırmızı et tüketiminin ise düşük olduğu bir diyet modeli olarak tanımlanmaktadır (12). Akdeniz diyetinin inflamatuvar bir hastalık olan RA üzerindeki olumlu etkileri, bu diyetin taze sebze ve meyveler (antioksidan vitaminlerden zengin), balık (anti-inflamatuvar özellikteki omega-3 çoklu doymamış yağ asitlerinden zengin) ve zeytinyağ (oleik asit, E vitamini, karotenler ve flavonoidler gibi antioksidanlardan zengin) gibi bileşenleri ile ilişkilendirilmektedir. Ayrıca Akdeniz diyetinde orta düzeyde tüketimi önerilen kırmızı şarap, akut ve kronik inflamasyona karşı koruyucu etkisi olduğu bilinen polifenolik bileşikler açısından da zengin bir içecektir (13).

Akdeniz diyetinin inflamatuvar belirteçlerde, hastalık aktivitesinde ve kardiyovasküler risk faktörlerinde azalma sağlayabileceği belirtilmiştir. Sköldstam et al. (14) 2003 yllında RA'li hastalarda 12 haftalık Akdeniz diyeti uygulamasının, inflamasyonu azalttığı ve fiziksel fonksiyonları iyileştirdiğini göstermiştir.

İnflamasyonla ilişkili durumlarda Akdeniz diyetinin olumlu etkileri gösterilmiş olsa da RA'nın önlenmesi ve tedavisindeki rolü ile ilgili kanıtlar yetersizdir (15). Forsyth et al. (16) 2018 yllında yaptığı sistematik bir derlemede, romatoid artritin önlenmesinde Akdeniz diyetinin önerilmesine ilişkin yeterli kanıt bulunmamakla birlikte, bu diyetin RA'lı bireylerde ağrıyı azaltmada ve fiziksel işlevleri arttırmada etkili olduğu belirtilmiştir. Akdeniz diyetine uyum ile RA riski arasındaki ilişkinin araştırıldığı bir vaka-kontrol çalışması olan İsveç Romatoid Artrit Epidemiyolojik Araştırması'nda (Swedish Epidemiological Investigation of RA-EIRA); beden kütle indeksi (BKI), eğitim düzeyi, fiziksel aktivite, besin takviyesi kullanımı, enerji tüketimi ve sigara kullanımı için düzeltme yapıldıktan sonra, Akdeniz diyetine yüksek uyumun (Akdeniz diyet skoru 6-9 puan), düşük uyuma (Akdeniz diyet skoru 0-2 puan) göre RA gelişme riskini \%21 azalttığı saptanmıştır. Yapılan bu çalışmada, Akdeniz diyet skoru ile RA riskinin ters ilişkili olduğu, ancak bu ilişkinin sadece erkeklerde ve seropozitif RA'da görüldüğü bildirilmiştir (17). Akdeniz diyeti ile RA riski arasındaki ilişkinin değerlendirilmesi amacıyla, Hemşireler Sağlık Çalışması (Nurses' Health Study-NHS) (1980-2008) ve NHS-II (1991-2009)'ye katılan, temel bağ dokusu hastalığı olmayan, sırasıyla 83.245 ve 91.393 kadın prospektif olarak takip edilmiştir. Çeşitli yaşam tarzı ve diyet değişkenleri için düzeltme yapıldıktan sonra, her iki kohort grubunda da Akdeniz diyetine uyumun artışı RA riski ile ilişkili bulunmamıştır (18). Dinamik bir egzersiz programı ile birlikte Akdeniz diyetinin, RA'lı kadınlarda sağlıkla ilişkili yaşam kalitesi üzerine etkisini değerlendirmek amacıyla yapılan randomize klinik bir çalışmaya 144 hasta katılmıştır. Romatoid artritli hastalar; Akdeniz diyeti (AD)+dinamik egzersiz programı (DEP) $(n=36)$, sadece DEP ( $n=37)$, sadece AD $(n=40)$ ve kontrol grubu $(n=31)$ olmak üzere 4 gruba ayrılmıştır. Sağlıkla ilişkili yaşam kalitesinde, AD+DEP ve DEP gruplarındaki 15 puanlık artışa karşılık AD grubunda 3.5 puanlık artış görülürken; kontrol grubunda 4.6 puanlık bir azalma olduğu bildirilmiştir. Ayrıca, 24 haftalık müdahaleden sonra fiziksel bileşen skorlarının $\mathrm{AD}+\mathrm{DEP}$ grubunda (15.5 puan), DEP grubunda (12 puan) ve AD grubunda (5.1 puan) arttığı, kontrol grubunda (1.7 puan) ise azaldığı saptanmıştır. Bu çalışmada, $\mathrm{AD}+\mathrm{DEP}$ birlikte uygulanmasının, hastalığ romatizmal ilaç kullanan ve düşük hastalık aktivitesi olan RA hastalarında yaşam kalitesini artırabileceği bildirilmektedir (19). 
Anti-inflamatuvar diyet ise genel olarak Akdeniz diyetine benzeyen, ancak potansiyel antiinflamatuvar bileşen içeriği Akdeniz diyetinden daha yüksek olduğu bildirilen bir diyettir. Bu diyetin, inflamasyon süreçlerinde etkili olan IL-1, IL-6 ve TNF-a gibi belirteçlerin gen ekspresyonunu azaltarak etkili olabileceği düşünülmektedir (10). Romatoid artritli hastalar için anti-inflamatuvar diyet içeriği tasarlanan bir araştırmada; rafine edilmiş tahıllar, kırmızı et, gluten, trans yağ asitleri, doymuş yağ asitleri gibi besin ve besin ögeleri "pro-inflamatuvar" olarak tanımlanmıştır. Omega-3 yağ asitleri, tekli doymamış yağ asitleri, antioksidanlar, fitokimyasallar, flavonoidler, D vitamini, papain ve bromelin gibi proteolitik enzimleri içeren meyveler (papaya, mango, ananas), zencefil, zerdeçal, karabiber, yeşil çay ve kurubaklagillerin ise inflamasyon üzerine yararlı etkileri olduğu bildirilmiştir (20). Antiinflamatuvar diyet; meyve (özellikle böğürtlengiller), sebze, kurubaklagiller, yağlı tohumlar ve sert kabuklu yemişler gibi bitkisel kaynaklı besinler ile tavuk, balık (kırmızı et yerine) gibi hayvansal kaynaklı besinlerin tüketimini artırmayı, işlenmiş ve fast food türü besinler, özellikle fruktoz ve sukroz gibi şekerlerin tüketimini azaltmayı amaçlar (10).

Anti-inflamatuvar diyetin bileşenlerinden olan omega-3 yağ asitlerinin RA'll hastalarda sabah tutukluğunu, hassas eklem sayısını ve şişmiş eklem sayısını azalttığı gösterilmiştir (21). Omega-3 yağ asitlerinin ağrı üzerine etkilerinin değerlendirildiği 18 randomize klinik çalışmadan oluşan 1143 RA'lı hastayı kapsayan sistematik derlemede, 2.1-9.1 g/ gün omega-3 takviyesinin ağrı düzeyi üzerine etkisi değerlendirilmiştir. Toplam 18 çalışmanın 10'unda omega-3 takviyesi ile ağrının azaldığı belirtilmiş, çalışmaların çoğunda 3-6 g/gün omega-3 yağ asidi alımının ağrı üzerinde etkili olduğu belirtilmiştir (22). Tedeschi et al. (23) yürüttüğü kesitsel bir araştırmada ise haftada iki ya da daha sık balık tüketen RA'lı hastalarda hiç balık tüketmeyen ya da ayda bir kez ya da daha az tüketenlere göre CRP ve hastalık aktivite skorlarının (DAS-28) anlamlı olarak daha düşük olduğu belirlenmiştir (23).
Romatoid artritli hastalarda anti-inflamatuvar diyetin hastalık aktivitesi üzerine etkisini araştırmak amacıyla yapılan çalışmalar kısıtlıdır. Bu konu ile ilgili İsviçre'de RA'lı hastalar üzerinde tek kör, randomize, çapraz bir çalışma yapılmıştır. Hastalar çalışma başlangıcında 10 hafta boyunca uygulanmak üzere müdahale ve kontrol diyet gruplarına randomize edilmiştir. Dört aylık arınma periyodundan sonra gruplar çaprazlanarak 10 hafta boyunca tekrar müdahale ve kontrol diyeti uygulanmıştır. Müdahale diyeti; 3-4 kez/hafta balık (ağırlıklı olarak somon), 1-2 kez/hafta kurubaklagil ile patates, tam tahillar, meyveler (nar, yaban mersini), sebzeler, az yağlı süt, yoğurt, yağlı tohumlar, probiyotikli meyve suları ve baharatları içermektedir. Hastalık Aktivite Skoru 28-Eritrosit Sedimentasyon Hızı'nın (DAS28-ESH), kontrol periyoduna göre müdahale periyodundan sonra daha düşük olduğu saptanmıştır, ancak müdahale ve kontrol periyotları arasında DAS28ESH açısından anlamlı bir fark bulunmamıştır (24). Araştırma sonucunda, RA'lı hastalarda bir adjuvan tedavi olarak önerilen bir anti-inflamatuvar diyetin olumlu etkilerinin gösterildiği, bu diyetin RA hastalık aktivitesi üzerine etkilerini belirlemek için ek çalışmalara ihtiyaç olduğu belirtilmiştir.

\section{Glutensiz Diyet}

Gluten buğday, arpa, yulaf ve çavdarda bulunan bir proteindir (25). Çölyak hastalarının tıbbi beslenme tedavisinde kullanılan glutensiz diyetin RA hastalarında da kullanılabileceği düşünülmektedir. $\mathrm{Bu}$ durum, insan lökosit antijenleri (HLA) ile ilişkili olan çölyak hastalığ (HLA-DQA1*05:01 ve HLADQB1*02:01 haplotipleri) ve RA (HLA-DRB1*04) arasındaki mekanistik benzerlikler ile açıklanabilir. Ayrıca, RA hastalarında yüksek oranda antigliadin antikorlarının varlığı glutensiz diyetin uygulanabileceğini desteklemektedir (11). Çölyak hastalığı fenotipik olarak RA'dan farklıdır, ancak son zamanlarda her iki hastalıkta da semptomatik bir örtüşme tanımlanmıştır. Çölyak hastaları artralji, artrit, poliartralji, sabah tutukluğu, subklinik sinovit, sırt ağrıları ve sakroileit gibi romatolojik belirtiler 
gösterebiliyorken, RA hastalarında da bağırsak semptomları görülebilmektedir. Son yıllarda çölyak hastalarında preklinik romatoid artrit de tanımlanmıştır. Ayrıca, her iki hastalıkta da benzer çevresel ve genetik özellikler gözlenmiştir. Bununla birlikte, çölyak ve RA hastalarında benzer özelliklerin veya serolojinin varlığını değerlendiren ayrıntılı çalışmalar halen bulunmamaktadır $(26,27)$.

Diyet gluteni, son zamanlarda pro-inflamatuvar, pro-oksidatif, anti-apoptotik ve düzenleyici $\mathrm{T}$ hücreleri üzerinde olumsuz etkisi olan, doğuştan gelen bağışıklık sisteminin bir aktivatörü olarak tanımlanmıştır (27,28). Glutenin mikrobiyomu etkileyebileceği, bağırsak geçirgenliğini ve oksidatif stresi artırabileceği bildirilmiştir. Glutenin aynı zamanda immünojenik, sitotoksikve pro-inflamatuvar olduğu; gluten alımının apoptozu artırabileceği, hücre canlılığı ve farklılaşmasını ise azaltabileceği ifade edilmektedir (29).

Mevcut kanitlar sinırlı olsa da glutensiz ve elementel diyetlerin RA hastalarinda olumlu etkileri gösterilmiştir (30). Glutensiz diyet tüketen çölyak hastalarının yaklaşık \%30’unda romatolojik belirtilerin iyileştiği veya ortadan kalktığı bildirilmiştir (31,32). Özellikle gluten içermeyen vegan diyetin RA hastalarında iyileşme sağladığı bildirilmiştir (10). Glutensiz vegan diyetin RA üzerine etkilerinin araştırıldığı bir çalışmada, 66 RA hastası bir yll süre ile glutensiz vegan diyet $(n=38)$ veya vegan olmayan dengeli bir diyet $(n=28)$ ile beslenmek üzere randomize edilmiştir. Bir yll sonra, glutensiz vegan diyet grubunda immünoglobulin G (IgG) anti-gliadin ve anti- $\beta$-laktoglobulin düzeylerinin anlamlı derecede azaldığı tespit edilmiştir. Bu çalışmada, glutensiz vegan diyetin artrit üzerindeki yararlı etkilerinin, diyetten çıkarılan besin antijenlerine karşı immün yanıtta azalma ile ilişkili olabileceği bildirilmiştir (33).

Romatoid artritli hastalarda, normal veya azalmış düşük yoğunluklu lipoprotein (LDL) kolesterol, azalmış yüksek yoğunluklu lipoprotein (HDL) kolesterol ve yüksek trigliserit (TG) düzeyleri ile karakterize edilen dislipidemi görülebilmektedir.
$\mathrm{Bu}$ nedenle ateroskleroz ve diğer kardiyovasküler hastalık riski bu hastalarda daha yüksektir (25). Yapılan bir çalışmada, bir yıl süren glutensiz vegan diyet müdahalesinin RA'lı hastalarda LDL-kolesterol, toplam kolesterol, okside LDL ve CRP düzeyleri ile DAS28 skorunu azalttığı gösterilmiş, glutensiz vegan diyetinin potansiyel olarak ateroprotektif ve anti-inflamatuvar değişiklikler sağlayabileceği bildirilmiştir (34). Yapılan farklı bir çalışmada, 7-10 günlük açlık sonrası, 3.5 ay glutensiz vegan diyet ve ardından 9 ay laktovejeteryan diyet uygulayan RA'lı hastaların klinik ve biyokimyasal bulgularında iyileşme olduğu görülmüştür. Bu yararlı etkinin, diyetteki değişikliklere bağlı olarak mikroflorada meydana gelen değişikliklerden kaynaklanabileceği ifade edilmiştir (35).

\section{SONUÇ VE ÖNERİLER}

Romatoid artrit kronik, ilerleyici, inflamatuvar otoimmün bir hastalıktır. Beslenme, RA gelişme riskini etkilemekle birlikte RA tanısı konmuş hastalarda hastalık aktivitesinde de değişikliklere neden olabilmektedir. Bu derleme kapsaminda ele alınan Akdeniz diyeti ve anti-inflamatuvar diyet; sebze ve meyve, tam tahıllar, kurubaklagiller ve yağlı tohumlar gibi bitkisel besinlerin daha fazla tüketimini, kırmızı et yerine balık veya kümes hayvanlarının tüketimini önermektedir. $\mathrm{Bu}$ diyet modellerine uygun beslenme, inflamatuvar belirteçleri azaltarak veya antioksidan savunmayı artırarak, hastalık aktivitesinin ve kardiyovasküler risk faktörlerinin azalmasında etkili olabilmektedir. Mevcut kanitlar sinırlı olsa da glutensiz vegan diyetlerin RA hastalarında ateroprotektif ve anti-inflamatuvar etkileri gösterilmiştir. Bu üç farklı diyet modelinin hastalık aktivitesini azaltmada yararlı etkileri olduğunu gösteren çalışmalar bulunmakla birlikte kanıtlar çelişkili ve yetersizdir. Diyet müdahalesine yönelik yürütülen klinik çalışmaların planlanmasının ve uygulanmasının zor olduğu düşünülmektedir. Araştırmaya katılan hastalar uzun süre diyete uyum gösteremeyebileceğinden araştırmalarda izlemden çıkan hasta oranları yüksek olabilmektedir. Bu 
gibi nedenlerle, bu diyet modelleri ile ilgili yapılan çalışmalarda farklı sonuçlar elde edilmiş olabilir.

Romatoid artritli bireylerde hastalık sürecinin sistemik etkilerini belirlemek için bu bireylerin beslenme durumlarının diyetisyen tarafindan değerlendirilmesi elzemdir. Bireylerin besin ve besin ögesialımları ayrıntılı değerlendirilmeli, biyokimyasal bulgulara, hastanın durumuna ve hastalığın klinik seyrine göre beslenme tedavileri bireye özgü olarak geliştirilmelidir.

Çıkar çatışması - Conflict of interest: Yazarlar çıkar çatışması olmadığını beyan ederler. - The authors declare that they have no conflict of interest.

\section{KAYNAKLAR}

1. Uhlig T, Moe RH, Kvien TK. The burden of disease in rheumatoid arthritis. Pharmacoeconomics. 2014;32(9):841-51.

2. Kourkouta L, Theodoridis X, Iliadis C, Ziogou T. Nutrition in rheumatoid arthritis. IJEAS. 2017;4(11):33-5.

3. Sahebari M, Ayati R, Mirzaei H, Sahebkar A, Hejazi S, Saghafi M, et al. Serum trace element concentrations in rheumatoid arthritis. Biol Trace Elem Res. 2016;171(2):237-45.

4. Kaplan MJ. Cardiovascular complications of rheumatoid arthritis: assessment, prevention, and treatment. Rheum Dis Clin North Am. 2010;36(2):405-26.

5. Keysser G. Are there effective dietary recommendations for patients with rheumatoid arthritis? Z Rheumatol. 2001;60(1):17-27.

6. Carocho M, Ferreira IC. A review on antioxidants, prooxidants and related controversy: Natural and synthetic compounds, screening and analysis methodologies and future perspectives. Food Chem Toxicol. 2013;51:15-25.

7. Plasqui G. The role of physical activity in rheumatoid arthritis. Physiol Behav. 2008;94(2):270-5.

8. Elma Ö, Tümkaya Yilmaz S, Deliens T, Coppieters I, Clarys P, Nijs J, et al. Do nutritional factors interact with chronic musculoskeletal pain? A systematic review. J Clin Med. 2020;9(3):702.

9. Oğur H, Günaydın R, Rakıcıoğlu N. Romatoid artritlikadın hastalarda beslenme durumunun değerlendirilmesi. Bes Diy Derg. 2020;48(1):63-72.
10. Gómez EF, Kaufer-Horwitz M, Mancera-Chávez GE. Medical Nutrition Therapy for Rheumatic Disease. In: Mahan KL, Raymond JL, editors. Krause's Food \& The Nutrition Care Process-E Book. 14th ed. Kanada: Elsevier Health Sciences; 2017.p. [790-805].

11. Lerner BA, Green PHR, Lebwohl B. Going against the grains: gluten-free diets in patients without celiac disease-worthwhile or not? Dig Dis Sci. 2019;64(7):17407.

12. Bach-Faig A, Berry EM, Lairon D, Reguant J, Trichopoulou A, Dernini S, et al. Mediterranean diet pyramid today. Science and cultural updates. Public Health Nutr. 2011;14(12a):2274-84.

13. Oliviero F, Punzi L, Spinella P. Mediterranean food pattern in rheumatoid arthritis. Curr Rheumatol Rev. 2009;5:233-40.

14. Sköldstam L, Hagfors L, Johansson G. An experimental study of a Mediterranean diet intervention for patients with rheumatoid arthritis. Ann Rheum Dis. 2003;62(3):208-14.

15. Vitetta L, Coulson S, Schloss J, Beck SL, Allen R, Sali A. Dietary recommendations for patients with rheumatoid arthritis: A review. Nutrition and Dietary Supplements. 2012;4:1-15.

16. Forsyth C, Kouvari M, D'Cunha NM, Georgousopoulou EN, Panagiotakos DB, Mellor DD, et al. The effects of the Mediterranean diet on rheumatoid arthritis prevention and treatment: A systematic review of human prospective studies. Rheumatol Int. 2018;38(5):737-47.

17. Johansson K, Askling J, Alfredsson L, Giuseppe DD, EIRA study group. Mediterranean diet and risk of rheumatoid arthritis: A population-based case-control study. Arthritis Res Ther. 2018;20(1):175.

18. Hu Y, Costenbader KH, Gao X, Hu FB, Karlson EW, Lu B. Mediterranean diet and incidence of rheumatoid arthritis in women. Arthritis Care Res (Hoboken). 2015;67(5):597-606.

19. García-Morales JM, Lozada-Mellado M, Hinojosa-Azaola A, Llorente L, Ogata-Medel M, Pineda-Juárez JA, et al. Effect of a Dynamic Exercise Program in combination with Mediterranean diet on quality of life in women with rheumatoid arthritis. J Clin Rheumatol. 2020; 26(7S Suppl 2):S116-S122.

20. Bustamante MF, Agustín-Perez M, Cedola F, Coras $\mathrm{R}$, Narasimhan R, Golshan S, et al. Design of an anti-inflammatory diet (ITIS diet) for patients with rheumatoid arthritis. Contemporary Clinical Trials Communications. 2020;17:100524.

21. Rajaei E, Mowla K, Ghorbani A, Bahadoram S, Bahadoram M, Dargahi-Malamir M. The effect of omega-3 fatty acids in patients with active rheumatoid arthritis receiving DMARDs therapy: Double-blind randomized controlled trial. Glob J Health Sci. 2015;8(7):18-25. 
22. Abdulrazaq M, Innes JK, Calder PC. Effect of $\omega-3$ polyunsaturated fatty acids on arthritic pain: A systematic review. Nutrition. 2017;39-40:57-66.

23. Tedeschi SK, Bathon JM, Giles JT, Lin TC, Yoshida K, Solomon DH. Relationship between fish consumption and disease activity in rheumatoid arthritis. Arthritis Care Res (Hoboken). 2018;70(3):327-32.

24. Vadell AKE, Bärebring L, Hulander E, Gjertsson I, Lindqvist HM, Winkvist A. Anti-inflammatory diet in rheumatoid arthritis (ADIRA)-a randomized, controlled crossover trial indicating effects on disease activity. Am J Clin Nutr. 2020;111(6):1203-13.

25. El-Chammas K, Danner E. Gluten-free diet in nonceliac disease. Nutr Clin Pract. 2011;26(3):294-9.

26. Fayyaz B, Gunawan F, Rehman HJ. 'Preclinical' rheumatoid arthritis in patients with celiac disease: A cross-sectional study. J Community Hosp Intern Med Perspect. 2019;9(2):86-91.

27. Aaron L, Patricia W, Ajay R, Francois L, Torsten M. The gut feeling of the joints: Celiac disease and rheumatoid arthritis are related. Int J Celiac Dis. 2019;7(1):21-5.

28. Warjri SB, Ete $\mathrm{T}$, Beyong $\mathrm{T}$, et al. Coeliac disease with rheumatoid arthritis: An unusual association. Gastroenterol Res. 2015;8(1):167-8.

29. Lerner A, Shoenfeld Y, Matthias T. Adverse effects of gluten ingestion and advantages of gluten withdrawal in nonceliac autoimmune disease. Nutr Rev. 2017;75(12):1046-58.

30. Badsha $H$. Role of diet in influencing rheumatoid arthritis disease activity. Open Rheumatol J.2018;12:1928.

31. Lubrano E, Ciacci C, Ames PR, Mazzacca G, Oriente P, Scarpa R. The arthritis of coeliac disease: Prevalence and pattern in 200 adult patients. Br J Rheumatol. 1996;35(12):1314-8.

32. Lerner A, Matthias T. Rheumatoid arthritis-celiac disease relationship: Joints get that gut feeling. Autoimmun Rev. 2015;14(11):1038-47.

33. Hafström I, Ringertz B, Spångberg A, von Zweigbergk L, Brannemark S, Nylander I, et al. A vegan diet free of gluten improves the signs and symptoms of rheumatoid arthritis: The effects on arthritis correlate with a reduction in antibodies to food antigens. Rheumatology (Oxford). 2001;40(10):1175-9.

34. Elkan AC, Sjöberg B, Kolsrud B, Ringertz B, Hafström I, Frostegård J. Gluten-free vegan diet induces decreased LDL and oxidized LDL levels and raised atheroprotective natural antibodies against phosphorylcholine in patients with rheumatoid arthritis: A randomized study. Arthritis Res Ther. 2008;10(2):R34.

35. Kjeldsen-Kragh J. Rheumatoid arthritis treated with vegetarian diets. Am J Clin Nutr. 1999;70:594-600. 